\title{
AVALIAÇÃO ECONÔMICA DO USO DA ADUBAÇÃO VERDE NA RECUPERAÇÃO DE ÁREAS DEGRADẢDAS
}

\section{ECONOMIC EVALUATION OF THE USE OF GREEN MANURE IN THE RECOVERY OF DEGRADED AREAS}

Rodrigo da Silva Santos ${ }^{1}$; Guilherme Alexandre Pacheco Gut ${ }^{2}$; Roseli Freire de Melo ${ }^{3}$; Daniel Maia Nogueira ${ }^{4}$; João Virgínio Emerenciano Neto ${ }^{5}$

DOI: https://doi.org/10.31692/978-65-991061-7-0.386-391

\section{INTRODUÇÃO}

Mais de $70 \%$ dos cerca de 117 milhões de hectares de pastagens cultivadas no Brasil apresenta algum grau de degradação, sendo o excesso de lotação e a ausência de reposição de nutrientes as principais causas dessa situação (MACEDO et al., 2014). Diante das pressões ambientais e de mercado, além dos incentivos do uso de novas tecnologias para a formação e manutenção das pastagens, tem-se observado uma mudança de atitude na produção animal a pasto no País, tornando evidente a grande possibilidade de um aumento de produtividade da pecuária pela simples recuperação de pastos degradados (DIAS-FILHO, 2014).

O plantio de leguminosas capazes de proporcionar boa cobertura vegetal e de formar simbiose com bactérias fixadoras de nitrogênio atmosférico e com fungos micorrizos, além de apresentar resultados satisfatórios, tem sido considerada uma prática viável na recuperação destas áreas (NOGUEIRA et al., 2012). Carvalho (2015) destaca o uso da adubação verde como uma alternativa promissora na recuperação de áreas degradadas de pastagens, enfatizando que essa prática promove o incremento de nitrogênio ao solo, seja através da fixação biológica ou pela incorporação de biomassa, garantindo economia no uso de fertilizantes nitrogenados.

Nesse contexto, o presente trabalho teve como objetivo verificar a viabilidade econômica da recuperação de áreas degradadas através da adubação verde.

\section{FUNDAMENTAÇÃO TEÓRICA}

A adubação verde é uma prática que aporta grande quantidade de matéria orgânica ao solo, através de exsudatos de raízes, biomassa radicular e foliar, ácidos orgânicos e várias

\footnotetext{
1 Graduando em Engenharia Agronômica, Universidade Federal do Vale do São Francisco, rodrigosilva1509@gmail.com

${ }^{2}$ Pós-Graduando em Ciência Animal, UNIVASF, gutguilherme@ gmail.com

${ }^{3}$ Embrapa Semiárido, roseli.melo@embrapa.br

${ }^{4}$ Embrapa Semiárido, daniel.nogueira@embrapa.br

${ }^{5}$ Programa de Pós-Graduação em Ciência Animal - UNIVASF, joao.emerencianoneto@univasf.edu.br
} 
substâncias elaboradas, melhorando as condições físicas e a ciclagem dos nutrientes do solo (DELARMELINDA et al., 2010). Segundo Alcântara et al. (2000), o seu uso promove efeitos positivos nas propriedades químicas do solo que variam em função da espécie utilizada, manejo dado à biomassa, época de plantio e corte, tempo de permanência dos resíduos no solo, condições locais e interação entre esses fatores.

Entre as espécies de plantas que são cultivadas com essa finalidade, destacam-se as leguminosas, pois, além de proporcionarem benefícios semelhantes aos de outras espécies, são capazes de acumular nitrogênio através da fixação biológica e produzir grande quantidade de massa rica em elementos minerais (PAULO et al., 2006).

A mucuna preta (Mucuna aterrima) possui rápido crescimento, grande rendimento de biomassa e ótima qualidade de matéria orgânica, sendo altamente recomendada para o uso como adubo verde. O feijão guandu (Cajanus cajan) é muito utilizado na melhoria de áreas instáveis, por ser bastante agressivo e apresentar um sistema radicular profundo. O feijão de porco (Canavalia ensiformis) se desenvolve bem em solos de baixa fertilidade e produz grande quantidade de massa por área, sendo bastante utilizado para esta finalidade. Outra opção é o lab-lab (Dolichos lablab), que apresenta um crescimento bastante vigoroso e elevada produção de biomassa, além de grande facilidade de decomposição no solo (PEREIRA, 2006).

$\mathrm{Na}$ escolha das espécies a serem utilizadas como adubo verde, é fundamental que o produtor conheça todos os custos envolvidos no processo produtivo, pois possibilita uma tomada de decisão mais correta. De acordo com Lopes e Carvalho (2002), o estudo dos custos permite verificar como os recursos investidos em um processo de produção estão sendo remunerados e como está a rentabilidade da atividade.

\section{METODOLOGIA}

O experimento foi realizado entre fevereiro e julho de 2018, na fazenda Milano, localizada na zona rural do município de Santa Maria da Boa Vista - PE ( $8^{\circ} 47^{\prime}$ Sul e $39^{\circ} 49^{\prime}$ Oeste, a uma altitude de 407 m). O clima da região, segundo a classificação de Köppen, é do tipo BSh. O solo do local encontrava-se em estado de degradação, sem nenhuma cobertura vegetal. O preparo da área foi feito de forma convencional com aração e gradagem, sendo incorporado ao solo $428 \mathrm{~kg} / \mathrm{ha}$ de calcário para correção da acidez.

A área total correspondia a 0,7 hectare e foi subdividida em quatro unidades de 1750 $\mathrm{m}^{2}$ cada, sendo os dados extrapolados para hectare. Os tratamentos consistiram em quatro consórcios de milheto com uma leguminosa (feijão guandu, mucuna preta, lab-lab e feijão de 
porco). A semeadura foi feita em sulcos de $25 \mathrm{~m}$, espaçados $1 \mathrm{~m}$ entre si, com as duas culturas na mesma linha de plantio. Foram utilizados $72 \mathrm{~kg} / \mathrm{ha}$ de sementes de milheto e $18 \mathrm{~kg} / \mathrm{ha}$ de sementes de cada leguminosa. No momento da semeadura, foi incorporado ao solo $1 \mathrm{~L}$ de esterco caprino por metro linear de sulco. A irrigação foi realizada por gotejo, quatro dias por semana, com tempo médio de irrigação de 3 horas/dia.

Afim de minimizar os custos de implantação, metade da biomassa produzida foi destinada para a produção de silagem (considerando $10 \%$ de perdas), sem comprometer a quantidade de biomassa a ser incorporada no solo (Tabela 1).

Tabela 1: Produção de biomassa de milheto em consórcio com leguminosas. Fonte: Própria

\begin{tabular}{ccccc}
\hline Variáveis & $\begin{array}{c}\text { Milheto }+ \\
\text { Feijão guandu }\end{array}$ & $\begin{array}{c}\text { Milheto }+ \\
\text { Mucuna } \\
\text { preta }\end{array}$ & $\begin{array}{c}\text { Milheto + } \\
\text { Lab-lab }\end{array}$ & $\begin{array}{c}\text { Milheto + } \\
\text { Feijão de porco }\end{array}$ \\
\hline Biomassa total (kg/ha) & $36.933,33$ & $47.616,67$ & $35.375,00$ & $38.525,00$ \\
Adubo verde (kg/ha) & $18.466,66$ & $23.808,33$ & $17.687,5$ & $19.262,5$ \\
Silagem (kg/ha) & $16.619,00$ & $21.427,50$ & $15.918,75$ & $17.336,25$ \\
\hline
\end{tabular}

O método de custo utilizado foi o do sistema de Custo Operacional Total, do Instituto de Economia Agrícola, proposto por Matsunaga et al. (1976). Para determinar o lucro total, foram calculados, para cada tratamento, os seguintes indicadores: receita bruta, obtida pela venda de silagem pelo preço médio do quilograma comercializado na região do Vale do são Francisco em agosto de 2018 ( $\mathrm{R} \$ 0,35$ por kg); o lucro operacional, calculado pela diferença entre a receita bruta e o custo operacional total. O custo de oportunidade foi calculado aplicando uma taxa de juros de $6 \%$ ao ano sobre o valor investido. No cálculo da depreciação utilizou-se uma vida útil de 10 anos para o sistema de irrigação. O custo com água de irrigação não foi contabilizado, além disso, não houve a necessidade de instalação de conjunto motobomba e gasto com energia elétrica, pois utilizou-se um sistema por gravidade direto do canal.

\section{RESULTADOS E DISCUSSÕES}

O valor gasto com o sistema de irrigação ( $\mathrm{R} \$ 2.984,22)$ foi considerado como um investimento, uma vez que o capital foi utilizado na aquisição de um bem, sendo contabilizado no custo total apenas o valor da parcela de sua depreciação (Tabela 2). O custo de oportunidade do capital não variou entre os sistemas, pois foi utilizada a mesma taxa de juros $(6 \%)$ sobre o valor investido. 
Tabela 2: Custos operacionais da produção de silagem e adubo verde em consórcio de milheto com leguminosas em área degradada. Fonte: Própria

\begin{tabular}{|c|c|c|c|c|}
\hline $\begin{array}{c}\text { Discriminação } \\
\text { (R\$/ha) }\end{array}$ & $\begin{array}{c}\text { Milheto + } \\
\text { Feijão guandu }\end{array}$ & $\begin{array}{c}\text { Milheto + } \\
\text { Mucuna preta }\end{array}$ & $\begin{array}{l}\text { Milheto + } \\
\text { Lab-lab }\end{array}$ & $\begin{array}{c}\text { Milheto + } \\
\text { Feijão de } \\
\text { porco }\end{array}$ \\
\hline Insumos & $\mathrm{R} \$ 1.611,42$ & $\mathrm{R} \$ 1.539,42$ & $\mathrm{R} \$ 1.467,42$ & $\mathrm{R} \$ 1.827,42$ \\
\hline Preparo do solo & 240,00 & 240,00 & 240,00 & 240,00 \\
\hline Semeadura & 128,00 & 128,00 & 128,00 & 128,00 \\
\hline Colheita e ensilagem & 411,26 & 530,41 & 394,03 & 429,18 \\
\hline Roçagem e gradagem & 168,88 & 168,88 & 168,88 & 168,88 \\
\hline Custo Operacional & $\mathrm{R} \$ 2.559,56$ & $\mathrm{R} \$ 2.606,71$ & $\mathrm{R} \$ 2.398,33$ & $\mathrm{R} \$ 2.793,48$ \\
\hline Depreciação & 298,42 & 298,42 & 298,42 & 298,42 \\
\hline Custo de oportunidade & 179,05 & 179,05 & 179,05 & 179,05 \\
\hline Custo Total & $\mathrm{R} \$ 3.037,03$ & $\mathrm{R} \$ 3.084,18$ & $\mathrm{R} \$ 2.875,80$ & $\mathrm{R} \$ 3.270,95$ \\
\hline Custo do $\mathrm{kg}$ de silagem & 0,16 & 0,13 & $\mathrm{R} \$ \quad 0,16$ & 0,17 \\
\hline Custo do kg de adubo & 0,13 & 0,10 & 0,13 & 0,14 \\
\hline
\end{tabular}

Os itens mais importantes do processo produtivo foram os insumos, que representaram de 49,91 a 55,87\% do custo total. Nessa perspectiva, é importante realizar pesquisas de mercado e definir estratégias de compra que possibilitem reduzir os custos de produção, principalmente na aquisição de insumos.

Os custos com insumos variaram apenas em função do valor das sementes das leguminosas, uma vez que foram utilizadas as mesmas quantidades de sementes de milheto, esterco e calcário em todos os sistemas. Diante disto, o custo com insumos foi maior no consórcio com feijão de porco, dado o maior custo do quilo desta semente, o que resultou em maior custo operacional.

Os custos com as operações de colheita e ensilagem variaram em função da produtividade obtida, sendo o maior valor gasto no consórcio entre milheto e mucuna preta, justificado pelo maior tempo de maquinário necessário para o corte e maior demanda de mão de obra para ensilar a forragem. Por outro lado, a maior biomassa produzida nesse consórcio (47.62 t/ha) possibilitou uma maior diluição dos custos de produção por quilo de silagem e adubo verde. Logo, percebe-se a importância de se obter elevado rendimento de biomassa por unidade de área.

As maiores receitas foram obtidas no consórcio entre milheto e mucuna (Tabela 3), este resultado é atribuído a maior remuneração obtida pela venda de silagem, visto que, como já mencionado, a maior produção de biomassa foi obtida nesse consórcio. Vale destacar que é interessante estar ciente da demanda pelo produto em questão antes de produzi-lo, para que o mesmo não seja perdido. 
Tabela 3: Receitas e indicadores econômicos da produção de silagem e de adubo verde em consórcio de milheto com leguminosas em área degradada. Fonte: Própria

\begin{tabular}{llccc}
\hline \multicolumn{1}{c}{ Variáveis (R\$/ha) } & $\begin{array}{c}\text { Milheto }+ \\
\text { Feijão guandu }\end{array}$ & $\begin{array}{c}\text { Milheto }+ \\
\text { Mucuna preta }\end{array}$ & $\begin{array}{c}\text { Milheto + } \\
\text { Lab-lab }\end{array}$ & $\begin{array}{c}\text { Milheto + } \\
\text { Feijão de porco }\end{array}$ \\
\hline Receita bruta & $\mathrm{R} \$ 5.817,00$ & $\mathrm{R} \$ 7.499,63$ & $\mathrm{R} \$ 5.571,56$ & $\mathrm{R} \$ 6.067,69$ \\
Lucro operacional & $\mathrm{R} \$ 3.257,44$ & $\mathrm{R} \$ 4.594,50$ & $\mathrm{R} \$ 2.874,81$ & $\mathrm{R} \$ 2.975,79$ \\
Lucro Total & $\mathrm{R} \$ 2.779,97$ & $\mathrm{R} \$ 4.415,45$ & $\mathrm{R} \$ 2.695,76$ & $\mathrm{R} \$ 2.796,74$ \\
\hline
\end{tabular}

Além da maior viabilidade econômica, do ponto de vista técnico, o consórcio entre milheto e mucuna preta também é mais favorável, pois tem maior potencial de recuperação da área em função da maior biomassa de adubo verde produzida (Tabela 1).

A lucratividade da recuperação das áreas foi positiva em todos os consócios, fato que reforça a aplicabilidade desta tecnologia. Segundo Leal et al. (2005), o preço e custo da produção do adubo verde são fatores essenciais levados em consideração pelos produtores para a adoção dessa prática.

\section{CONCLUSÕES}

O uso da adubação verde na recuperação de áreas degradadas é uma prática bastante viável e pode ser lucrativa. O consórcio entre milheto e mucuna preta foi o mais produtivo, enquanto que o consórcio com feijão de porco apresentou o maior custo de produção, entretanto todos os sistemas geraram receitas interessantes com a venda de silagem.

\section{REFERÊNCIAS}

ALCANTARA, F. A.; FURTINI NETO, A. E.; PAULA, M. B.; MESQUITA, H. A.; MUNIZ, J. A. Adubação verde na recuperação da fertilidade de um Latossolo Vermelho-Escuro degradado. Pesquisa Agropecuária Brasileira, v.35, p.277-288, 2000.

CARVALHO, A. M. Adubação verde pode melhorar a qualidade dos solos e ainda recuperar áreas degradadas. Disponível em: <http://www.sna.agr.br/adubacao-verde-podemelhorar-a-qualidade-dos-solos-e-ainda-recuperar-areas-degradadas/>. Acesso em: 03 set. 2018.

DELARMELINDA, E. A.; SAMPAIO, F. A. R.; DIAS, J. R. M.; TAVELLA, L. B.; SILVA, J. S. Adubação verde e alterações nas características químicas de um Cambissolo na região de Ji-Paraná-RO. Acta Amazonica, v.40, p.625-628, 2010.

DIAS-FILHO, M. B. Diagnóstico das Pastagens no Brasil. Belém: Embrapa Amazônia Oriental, 2014, 36p. (Embrapa Amazônia Oriental. Documentos, 402).

LEAL, A. J. F.; LAZARINI, E.; TARSITANO, M. A. A.; SÁ, M. E.; GOMES JÚNIOR, F. G. Viabilidade econômica da rotação de culturas e adubos verdes antecedendo o cultivo do milho em sistema de plantio direto em solo de cerrado. Revista Brasileira de 
Milho e Sorgo, v.4, p.298-307, 2005.

LOPES, M. A.; CARVALHO, F. M. Custo de produção do gado de corte. Lavras: UFLA, 2002. 47p. (Boletim Agropecuário, 47).

MACEDO, M. C. M.; ZIMMER, A. H.; KICHEL, A. N.; ALMEIDA, R. G.; ARAUJO, A. R. Degradação de pastagens, alternativas de recuperação e renovação, e formas de mitigação. In: ENCONTRO DE ADUBAÇÃO DE PASTAGENS DA SCOT CONSULTORIA - TEC FÉRTIL, 1., 2013, Ribeirão Preto, SP. Anais... Bebedouro: Scot Consultoria, p.158-181, 2014.

MATSUNAGA, M.; BEMELMANS, P. F.; TOLEDO, P. E. N.; DULLEY, R. D.; OKAWA, H; PEDROSO, I. A. (1976). Metodologia de custo de produção utilizada pelo IEA. Agricultura em São Paulo, 23:123-139.

NOGUEIRA, N. O.; OLIVEIRA, O. M.; MARTINS, C. A. S.; BERNARDES, C. O. Utilização de leguminosas para recuperação de áreas degradadas. Enciclopédia Biosfera, v.8, p.2012-2031, 2012.

PAUlO, E. M.; BERTON, R. S.; CAVICHIOLI, J. C.; BULISANI, E. A.; KASAI, F. S. Produtividade do cafeeiro Mundo Novo enxertado e submetido à adubação verde antes e após recepa da lavoura. Bragantia, v.65, p.115-120, 2006.

PEREIRA, A. R. Como selecionar plantas para áreas degradadas e controle de erosão. Belo Horizonte: Fapi, 2006. 88p. 